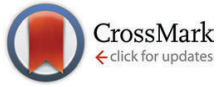

Cite this: Chem. Commun., 2015, 51,679

Received 3rd November 2014 Accepted 14th November 2014

DOI: $10.1039 / \mathrm{c} 4 \mathrm{cc} 08740 \mathrm{~b}$

www.rsc.org/chemcomm

\section{Impact of a rigid backbone on the structure of an agostically-stabilised dialkylstannylene: isolation of an unusual bridged stannyl-stannylene $\dagger$}

\author{
Keith Izod,* Casey M. Dixon, Ross W. Harrington and Michael R. Probert
}

\begin{abstract}
The reaction between the phosphine-borane-stabilised dicarbanion complex $\left[1,2-\mathrm{C}_{6} \mathrm{H}_{4}\left\{\mathrm{CHP}\left(\mathrm{BH}_{3}\right) \mathrm{Cy}_{2}\right\}_{2}\right]\left[\mathrm{Li}(\mathrm{THF})_{n}\right]_{2}$ and $\mathrm{Cp}_{2} \mathrm{Sn}$ gives the unusual stannyl-stannylene $\left[\left[1,2-\mathrm{C}_{6} \mathrm{H}_{4}\left\{\mathrm{CHP}\left(\mathrm{BH}_{3}\right) \mathrm{Cy}_{2}\right\}_{2}\right] \mathrm{Sn}\right]_{2} \cdot 1 \frac{1}{2} \mathrm{PhMe}$, in which one dicarbanion ligand chelates a tin centre, while the other bridges a tin-tin bond. The stannylene centre is stabilised by an agostic-type B-H...Sn interaction.
\end{abstract}

In the absence of sufficiently sterically demanding substituents, diorganostannylenes, $\mathrm{R}_{2} \mathrm{Sn}$, typically oligomerise to the corresponding polystannanes, $-\left(\mathrm{R}_{2} \mathrm{Sn}\right)_{n}-\left[\mathrm{R}=e . g\right.$. Et, Cy ${ }^{1}{ }^{1}$ With more hindered substituents, either distannenes $\mathrm{R}_{2} \mathrm{Sn}=\mathrm{SnR}_{2}(\mathrm{I}),{ }^{2}$ or monomeric stannylenes $\mathrm{R}_{2} \mathrm{Sn}$ (II) are isolated (Scheme 1); ${ }^{3}$ for certain substituents a dynamic equilibrium between the distannene and stannylene forms of these compounds has been observed in solution. ${ }^{2 b}$ Recently, Power and co-workers reported the terphenylsubstituted mixed valence stannyl-stannylenes $\mathrm{ArR}_{2} \mathrm{Sn}-\mathrm{SnAr}$ (III) $\left.\left[\mathrm{Ar}=\text { e.g. 2,6-(2,6-i } \mathrm{Pr}_{2} \mathrm{C}_{6} \mathrm{H}_{3}\right)_{2} \mathrm{C}_{6} \mathrm{H}_{3} ; \mathrm{R}=\mathrm{H}, \mathrm{Me}, \mathrm{Ph}\right],{ }^{4}$ while both Power and co-workers and Kira and co-workers have isolated a small number of bridged analogues. ${ }^{5}$ Such stannyl-stannylene compounds are formal isomers of distannenes, in which a tetravalent (formally $\mathrm{Sn}(\mathrm{III})$ ) and a divalent (formally $\mathrm{Sn}(\mathrm{I}$ )) centre are connected by a $\sigma$-bond. Calculations on III $(\mathrm{R}=\mathrm{H})$ suggest that this isomer is the global minimum on the potential energy surface, although the corresponding distannene (I) and hydride-bridged isomers $\operatorname{ArSn}(\mu-\mathrm{H})_{2} \operatorname{SnAr}(\mathbf{I V})$ are less stable by only 7-14 kcal mol ${ }^{-1} \cdot{ }^{4 d}$

We have recently shown that agostic-type B-H $\cdots \mathrm{E}$ interactions stabilise monomeric dialkylstannylenes, significantly disfavouring dimerisation to the corresponding distannene. ${ }^{6}$ For example, $\left[\left(\mathrm{Me}_{3} \mathrm{Si}\right)\left\{\mathrm{Me}_{2} \mathrm{P}\left(\mathrm{BH}_{3}\right)\right\} \mathrm{C}\right]_{2} \mathrm{Sn}(\mathbf{1}),{ }^{6 d}$ which exhibits two stabilising $\mathrm{B}-\mathrm{H} \cdots \mathrm{Sn}$ contacts, adopts a monomeric structure, whereas, $\left\{\left(\mathrm{Me}_{3} \mathrm{Si}\right)_{2} \mathrm{CH}\right\}_{2} \mathrm{Sn},{ }^{2 c}$ which is isoelectronic and isosteric with $\mathbf{1}$,

Main Group Chemistry Laboratories, School of Chemistry, Newcastle University, Newcastle upon Tyne NE1 7RU, UK. E-mail: keith.izod@ncl.ac.uk;

Fax: +44 (0)191208 6929; Tel: +44 (0)191208 7101

$\dagger$ Electronic supplementary information (ESI) available: Details of the synthesis of 5; details of the DFT studies of $5^{\prime}$, rac $^{\prime} \mathbf{6}^{\prime}$, and meso-6' ${ }^{\prime}$. CCDC 1010284. For ESI and crystallographic data in CIF or other electronic format see DOI: 10.1039/c4cc08740b<smiles>[R][SH+](C)=[Sn]([R])[R]</smiles>

(I)

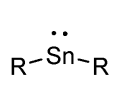

(II)

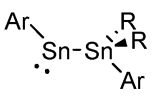

(III)

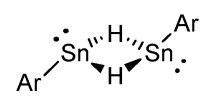

(IV)
Scheme 1

but which lacks such agostic-type interactions, dimerises to the corresponding distannene in the solid state. In all of the dialkylstannylenes we have isolated which exhibit these stabilising contacts (Scheme 2) the supporting ligand is either monodentate $(\mathbf{1}, \mathbf{4})$, or else has a flexible spacer group linking the two "carbanion" centres $(2,3)$. This permits the phosphine-borane group to tilt towards the tin centre, maximising overlap between the $\mathrm{B}-\mathrm{H}$-orbital and the vacant $\mathrm{p}$-orbital at tin and so providing the greatest possible stabilisation of the electron-poor tin(II) centre.

Recently we have begun to explore the chemistry of phosphineborane-stabilised dicarbanions in which the two carbanion centres are linked by an ortho-phenylene spacer. ${ }^{7}$ We were interested to explore the impact of such a rigid ligand backbone on the strength of the $\mathrm{B}-\mathrm{H} \cdots \mathrm{Sn}$ agostic-type interactions in the corresponding dialkylstannylene derivatives, since the rigidity of the ligand should limit the degree to which the borane group can position itself close to the tin atom and so moderate the strength of the stabilising B-H - . Sn interactions. We report herein our initial studies in this area and the unexpected isolation of an agostically-stabilised, bridged stannyl-stannylene.

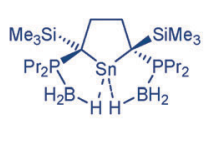

(2)

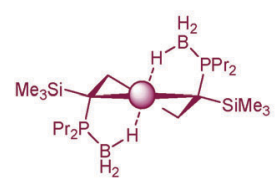

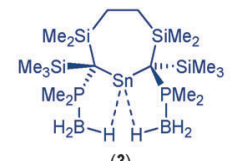

(3)

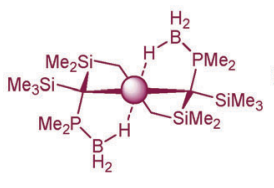

Scheme 2

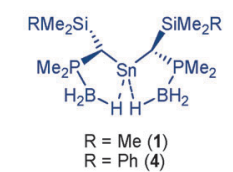

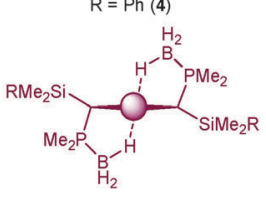




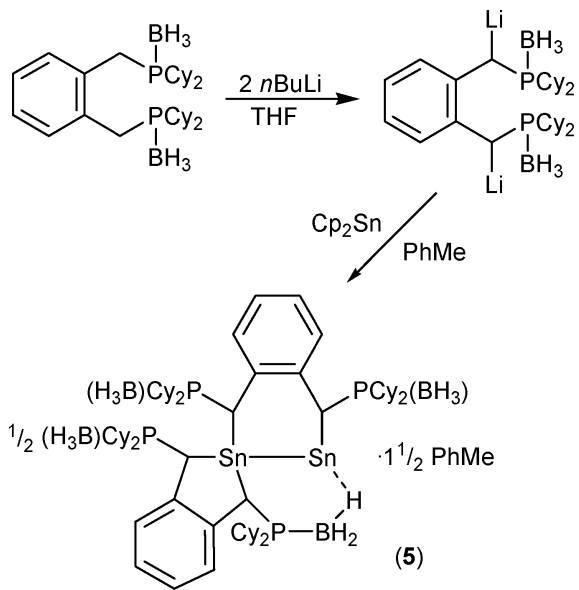

Scheme 3

The reaction between in situ-generated $\left[1,2-\mathrm{C}_{6} \mathrm{H}_{4}\left\{\mathrm{CHP}\left(\mathrm{BH}_{3}\right) \mathrm{Cy}_{2}\right\}_{2}\right]-$ $\left[\mathrm{Li}(\mathrm{THF})_{n}\right]_{2}^{7}$ and one equivalent of $\mathrm{Cp}_{2} \mathrm{Sn}^{8}$ in toluene gives a yellow solution containing pale solids of $\mathrm{CpLi}$ (Scheme 3). Removal of these solids by filtration, followed by concentration and cooling of the filtrate, yields pale yellow crystals of $\left[\left[1,2-\mathrm{C}_{6} \mathrm{H}_{4}\left\{\mathrm{CHP}\left(\mathrm{BH}_{3}\right) \mathrm{Cy}_{2}\right\}_{2}\right] \mathrm{Sn}\right]_{2}$. $1 \frac{1}{2} \mathrm{PhMe}(5)$ after 1 week.

Somewhat surprisingly, once isolated in the solid state, $\mathbf{5}$ has limited solubility in aromatic and ethereal solvents and reacts rapidly with chlorinated solvents. Compound $\mathbf{5}$ is also air-sensitive, decomposes on exposure to ambient light or temperatures above $c a .50{ }^{\circ} \mathrm{C}$, and, over a period of several hours, begins to decompose in THF solution at room temperature. Nonetheless, $\mathbf{5}$ is sufficiently soluble and stable in THF for limited characterisation by NMR spectroscopy (see below). Single crystals of $\mathbf{5}$ suitable for X-ray crystallography were obtained from a freshly-prepared sample in toluene.

Compound $\mathbf{5}$ crystallises as a discrete molecular species containing two distinct tin centres joined by a formal $\mathrm{Sn}-\mathrm{Sn}$ $\sigma$-bond and with $1 \frac{1}{2}$ molecules of toluene in the asymmetric unit (Fig. 1). $\neq$ The formal Sn(III) centre is bonded to the two carbon atoms of a chelating dicarbanion ligand [Sn(1)-C(1) 2.1887(17), $\mathrm{Sn}(1)-\mathrm{C}(8)$ $2.2021(18) \AA]$ and to a single carbon atom of the second dicarbanion ligand [Sn(1)-C(33) 2.2518(17) ̊], along with the short Sn-Sn contact. In contrast, the formal $\mathrm{Sn}(\mathrm{I})$ centre is bonded to the adjacent tin atom and a carbon atom of the second dicarbanion ligand [Sn(2)-C(40) 2.3250(18) $\mathrm{A}]$. In addition, $\mathrm{Sn}(2)$ has a short contact to a hydrogen atom of one of the $\mathrm{BH}_{3}$ groups of the ligand which chelates $\operatorname{Sn}(1)[\operatorname{Sn}(2) \cdots \mathrm{H}(2 \mathrm{~B}) 2.49(2) \AA]$. Although the location of $\mathrm{H}$ atoms by X-ray crystallography is rather imprecise, this distance is substantially shorter than the sum of the van der Waals radii of Sn and $\mathrm{H}(3.37 \AA)$, suggesting that there is a significant, agostic-type $\mathrm{B}-\mathrm{H} \cdots \mathrm{Sn}$ interaction. This distance is similar to the $\mathrm{H} \cdots \mathrm{Sn}$ distances in 1-4, which fall in the range 2.03(5)-2.41(8) $\AA^{6}{ }^{6}$

Thus, one phosphine-borane-stabilised carbanion ligand chelates $\mathrm{Sn}(1)$, generating a five-membered $\mathrm{C}_{4} \mathrm{Sn}$ heterocycle, while the second bridges $\mathrm{Sn}(1)$ and $\mathrm{Sn}(2)$, generating a $\mathrm{C}_{4} \mathrm{Sn}_{2}$ six-membered heterocycle; each of these ligands adopts a mesoconfiguration. The $\operatorname{Sn}(1)-\operatorname{Sn}(2)$ distance [2.81531(17) $\AA$ ] is substantially shorter than the Sn-Sn distances in the few previously

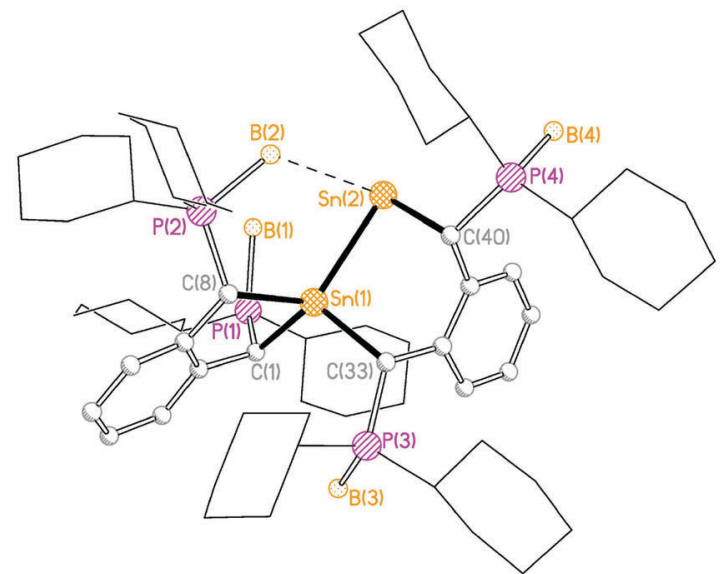

Fig. 1 Molecular structure of $\mathbf{5}$ with solvent of crystallisation and $\mathrm{H}$ atoms omitted for clarity. Selected bond lengths (Å): Sn(1)-Sn(2) 2.81531(17), Sn(1)-C(1) 2.1887(17), Sn(1)-C(8) 2.2021(18), Sn(1)-C(33) 2.2518(17), Sn(2)-C(40) 2.3250(18), $\mathrm{Sn}(2) \cdots H(2 B) \quad 2.49(2), \quad P(1)-B(1) \quad 1.931(2), \quad P(1)-C(1) \quad 1.8373(18), \quad P(1)-C(9)$ 1.8404(19), $P(1)-C(15)$ 1.8332(19), $P(2)-B(2)$ 1.927(2), $P(2)-C(8)$ 1.8290(18), $P(2)-C(21)$ 1.8413(18), $P(2)-C(27)$ 1.8406(19), $P(3)-B(3)$ 1.939(2), $P(3)-C(33)$ 1.8218(17), $P(3)-C(41) \quad 1.8550(19), P(3)-C(47)$ 1.841(2), $P(4)-B(4) \quad 1.934(2)$, $P(4)-C(40) 1.8103(18), P(4)-C(53) 1.8462(19), P(4)-C(59) 1.8368(19)$.

reported stannyl-stannylenes, which range from 2.865 to $2.9688(5) \AA \AA^{3,9}$ and is similar to the $\mathrm{Sn}-\mathrm{Sn}$ distance in grey tin $(2.80 \AA) .{ }^{10}$ We attribute the shortness of this distance to the incorporation of the Sn-Sn bond into a rigid six-membered ring.

DFT calculations on the model complex $\left[\left[1,2-\mathrm{C}_{6} \mathrm{H}_{4}\left\{\mathrm{CHP}\left(\mathrm{BH}_{3}\right)-\right.\right.\right.$ $\left.\left.\left.\mathrm{Me}_{2}\right\}_{2}\right] \mathrm{Sn}\right]_{2}\left(5^{\prime}\right)$, in which the cyclohexyl groups have been replaced by smaller methyl substituents, reproduce well the core structure of 5 observed in the solid state (Fig. 2). In particular, one of the borane hydrogen atoms lies close to the divalent Sn

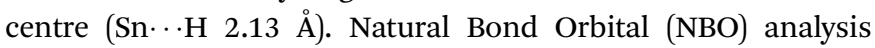
indicates that this interaction stabilises $5^{\prime}$ by $28.8 \mathrm{kcal} \mathrm{mol}^{-1}$, similar to the stabilisation energies calculated for 1-4 (in spite of the unusual bridging mode of the ligand in $\mathbf{5}^{\prime}$ ).

In order to estimate the stability of the stannyl-stannylene $\mathbf{5}^{\prime}$ in comparison to the putative monomer meso- $\left[1,2-\mathrm{C}_{6} \mathrm{H}_{4}\left\{\mathrm{CHP}\left(\mathrm{BH}_{3}\right)^{-}\right.\right.$ $\mathrm{Me}_{\left.2\}_{2}\right]} \mathrm{Sn}\left(\right.$ meso-6 $\left.{ }^{\prime}\right)$ we have calculated the energy of both this species and the corresponding rac isomer (Fig. 2). The optimised geometries for both meso- and rac-6' $\mathbf{6}^{\prime}$ exhibit a single short B-H $\cdots$. Sn contact with Sn $\cdots H$ distances of 2.15 and $2.13 \AA$, respectively. While for meso-6' this interaction leaves the $\mathrm{C}_{4} \mathrm{Sn}$ five-membered ring essentially planar, for rac-6' it results in a twisting of both the five-membered ring and the aromatic ring, such that the $\mathrm{C}-\mathrm{Sn}-\mathrm{C}$ plane lies at approximately $8^{\circ}$ to the mean plane of the aromatic backbone. NBO analysis suggests that the $\mathrm{B}-\mathrm{H} \cdots \mathrm{Sn}$ interactions stabilise meso- and rac-6 $\mathbf{6}^{\prime}$ by 41.4 and $33.1 \mathrm{kcal} \mathrm{mol}^{-1}$, respectively. Nonetheless, rac-6 ${ }^{\prime}$ is calculated to be $1.8 \mathrm{kcal} \mathrm{mol}^{-1}$ more stable than meso- $\mathbf{6}^{\prime}$. Comparison of the energy of meso- $^{\prime}{ }^{\prime}$ with that of the stannyl-stannylene $\mathbf{5}^{\prime}$ suggests that the latter is favoured by just $1.1 \mathrm{kcal} \mathrm{mol}^{-1}$.

$\mathrm{A}^{31} \mathrm{P}\left\{{ }^{1} \mathrm{H}\right\}$ NMR spectrum of the crude reaction solution, prior to the isolation of $\mathbf{5}$, consists of multiple broad and overlapping signals. This suggests that, in addition to $\mathbf{5}$, the solution contains the corresponding rac isomer, either as a monomeric or dimeric species; $§$ however, we have, as yet, been unable to isolate this species. 


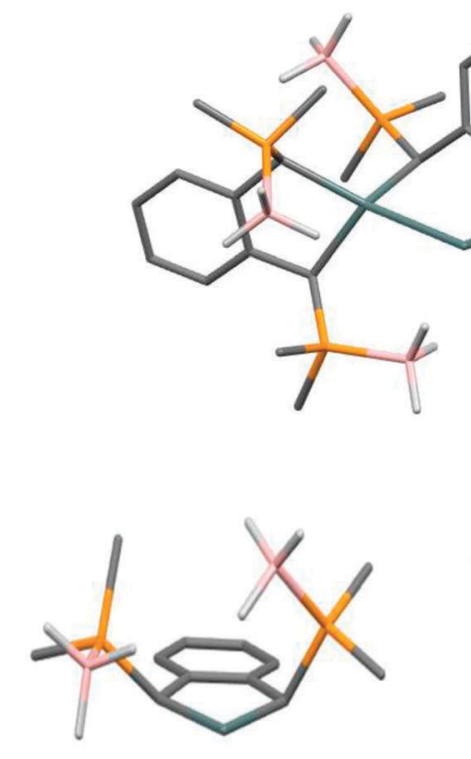

meso-6'

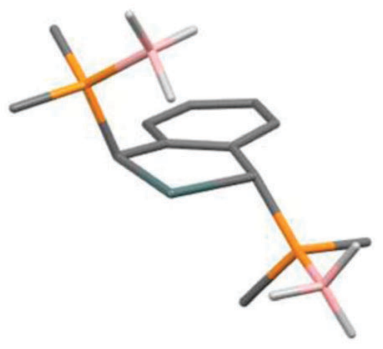

$\operatorname{rac}-\mathbf{6}^{\prime}$

Fig. 2 Optimised geometries of $5^{\prime}$, meso- $\mathbf{6}^{\prime}$ and rac $^{-\mathbf{6}^{\prime}}$ with $\mathrm{C}$-bound $\mathrm{H}$ atoms omitted for clarity [B3LYP/6-31G(2d,p)[LanL2DZ on Sn]] (C dark grey, $\mathrm{H}$ white, B pink, $\mathrm{P}$ orange, Sn light grey).

The ${ }^{1} \mathrm{H}$ NMR spectrum of 5 is complex and rather uninformative, due to the overlap of signals from the eight chemically inequivalent cyclohexyl groups (within which pairs of $\mathrm{CH}_{2}$ groups are diastereotopic) and the signals from the four chemically inequivalent benzylic and borane groups. However, the ${ }^{31} \mathrm{P}\left\{{ }_{1}^{1} \mathrm{H}\right\} \mathrm{NMR}$ spectrum of 5 exhibits four broad, approximately equal intensity signals at $27.2,28.6,30.0$, and $35.4 \mathrm{ppm}$, while the ${ }^{11} \mathrm{~B}\left\{{ }^{1} \mathrm{H}\right\}$ NMR spectrum exhibits two broad signals at -43.5 and $-38.8 \mathrm{ppm}$ in an approximately $1: 3$ ratio; in the latter case, we assign the unique high field signal to the phosphine-borane group associated with the short B-H $\cdots$ Sn interaction. These spectra indicate that the dinuclear structure of $\mathbf{5}$ observed in the solid state persists in solution. Consistent with this, the ${ }^{119} \mathrm{Sn}\left\{{ }_{\{}^{1} \mathrm{H}\right\}$ NMR spectrum of 5 exhibits broad, featureless signals at -103 and 339 ppm, which we attribute to the stannyl and stannylene centres, respectively; coupling between the two Sn centres is not resolved, due to the broad nature of these signals. The former signal is typical of tetravalent tin centres, while the latter is similar to the chemical shifts of the previously reported agostically-stabilised dialkylstannylenes 1-4, which fall into the range $320-787$ ppm. $^{6}$

In summary, while phosphine-borane-stabilised dicarbanions linked by a flexible aliphatic spacer group give the corresponding stannylene derivatives, the incorporation of a rigid ortho-phenylene spacer leads to the isolation of the stannyl-stannylene complex $\mathbf{5}$. Nonetheless, 5 exhibits an agostic-type B-H $\cdots$ Sn interaction which stabilises this complex by $28.8 \mathrm{kcal} \mathrm{mol}^{-1}$.

The authors would like to acknowledge the use of the EPSRC UK National Service for Computational Chemistry Software (NSCCS) at Imperial College London in carrying out this work.

\section{Notes and references}

\$ Crystal data for 5: $\mathrm{C}_{64} \mathrm{H}_{112} \mathrm{~B}_{4} \mathrm{P}_{4} \mathrm{Sn}_{2} \cdot 1.5 \mathrm{C}_{7} \mathrm{H}_{8}, \mathrm{FW}=1424.36$, monoclinic, $P 2_{1} / c, a=14.0885(1), b=26.5770(2), c=20.0509(2) \AA, \beta=95.2730(10)^{\circ}$,

$V=7475.89(11) \AA^{3}, Z=2, \mu=0.793 \mathrm{~mm}^{-1}$, final $R_{1}=0.028$ for $I>2 \sigma I$, $\mathrm{w} R_{2}=0.060$ for all data, GoF $=1.051$. CCDC 1010284 .

$\S$ The relatively low isolated yield of $5(28 \%)$ is a reflection of the mixture of isomers produced in this reaction; if an equal ratio of rac to meso isomers is assumed, then this equates to an isolated yield of $56 \%$ of the total meso diastereomer.

1 A. G. Davies, in Comprehensive Organometallic Chemistry III, ed. D. M. P. Mingos, R. H. Crabtree and C. E. Housecroft, Elsevier, Oxford, UK, 2007, ch. 3.14, vol. 3.

2 (a) P. J. Davidson and M. F. Lappert, J. Chem. Soc., Chem. Commun., 1973, 317; (b) K. W. Zilm, G. A. Lawless, R. M. Merrill, J. M. Millar and G. G. Webb, J. Am. Chem. Soc., 1987, 109, 7236; (c) D. E. Goldberg, D. H. Harris, M. F. Lappert and K. M. Thomas, J. Chem. Soc., Chem. Commun., 1976, 261; (d) M. Sturmann, W. Saak, K. W. Klinkhammer and M. Weidenbruch, Z. Anorg. Allg. Chem., 1999, 625, 1955; (e) T. Fukawa, V. Y. Lee, M. Nakamoto and A. Sekiguchi, J. Am. Chem. Soc., 2004, 126, 11758; $(f)$ D. Kurzbach, S. Yao, D. Hindenberger and K. W. Klinkhammer, Dalton Trans., 2010, 39, 6449; $(g)$ V. Y. Lee, T. Fukawa, M. Nakamoto, A. Sekiguchi, B. L. Tumanskii, M. Karni and Y. Apeloig, J. Am. Chem. Soc., 2006, 128, 11643; $(h)$ J. Henning and L. Wesemann, Angew. Chem., Int. Ed., 2012, 51, 12869.

3 For examples see: (a) P. Jutzi, A. Becker, H. G. Stammler and B. Neumann, Organometallics, 1991, 10, 1647; (b) M. Kira, R. Yauchibara, R. Hirano, C. Kabuto and H. Sakurai, J. Am. Chem. Soc., 1991, 113, 7785; (c) M. Kira, S. Ishida, T. Iwamoto and C. Kabuto, J. Am. Chem. Soc., 1999, 121, 9722; (d) M. Kira, S. Ishida, T. Iwamoto, M. Ichinohe, C. Kabuto, L. Ignatovich and H. Sakurai, Chem. Lett., 1999, 263; (e) C. Eaborn, M. S. Hill, P. B. Hitchcock, D. Patel, J. D. Smith and S. Zhang, Organometallics, 2000, 19, 49; $(f)$ C. Eaborn, T. Ganicz, P. B. Hitchcock, J. D. Smith and S. E. Sozerli, Organometallics, 1997, 16, 5621; $(g)$ A. D. Phillips, S. Hino and P. P. Power, J. Am. Chem. Soc., 2003, 125, 7520; (h) W. Setaka, K. Sakamoto, M. Kira and P. P. Power, Organometallics, 2001, 20, 4460; (i) B. E. Eichler, B. L. Phillips, P. P. Power and M. P. Augustine, Inorg. Chem., 2000, 39, 5450; $(j)$ H. Grutzmacher, H. Pritzkow and F. T. Edelmann, Organometallics, 1991, 10, 23; (k) S. Wingerter, H. Gornitzka, R. Bertermann, S. K. Pandey, J. Rocha and D. Stalke, Organometallics, 2000, 19, 3890; (l) C. Drost, P. B. Hitchcock, M. F. Lappert and L. J.-M. Pierssens, Chem. Commun., 1997, 1141; (m) L. Pu, A. D. Phillips, A. F. Richards, M. Stender, R. S. Simons, M. M. Olmstead and P. P. Power, J. Am. Chem. Soc., 2003, 125, 11626.

4 (a) A. D. Phillips, S. Hino and P. P. Power, J. Am. Chem. Soc., 2003, 125, 7520; (b) Y. Peng, M. Brynda, B. D. Ellis, J. C. Fettinger, E. Rivard and P. P. Power, Chem. Commun., 2008, 6042; (c) B. E. Eichler and P. P. Power, Inorg. Chem., 2000, 39, 5444; (d) E. Rivard, R. C. Fischer, R. Wolf, Y. Peng, W. A. Merrill, N. D. Schley, Z. Zhu, L. Pu, J. C. Fettinger, S. J. Teat, I. Nowik, R. H. Herber, N. Takagi, S. Nagase and P. P. Power, J. Am. Chem. Soc., 2007, 129, 16197; (e) H. Lei, J. C. Fettinger and P. P. Power, Organometallics, 2010, 29, 5585; $(f)$ P. P. Power, C. Stanciu, I. Nowik and R. H. Herber, Inorg. Chem., 2005, 44, 9461.

5 (a) W. Setaka, K. Hirai, H. Tomioka, K. Sakamoto and M. Kira, Chem. Commun., 2008, 6558; (b) S. Hino, M. M. Olmstead and P. P. Power, Organometallics, 2005, 24, 5484; (c) C. Stanciu, A. F. Richards and P. P. Power, J. Am. Chem. Soc., 2004, 126, 4106.

6 (a) K. Izod, W. McFarlane, B. V. Tyson, I. Carr, W. Clegg and R. W. Harrington, Organometallics, 2006, 25, 1135; (b) K. Izod, W. McFarlane, C. Wills, W. Clegg and R. W. Harrington, Organometallics, 2008, 27, 4386; (c) K. Izod, C. Wills, W. Clegg and R. W. Harrington, Organometallics, 2009, 28, 2211; (d) K. Izod, C. Wills, W. Clegg and R. W. Harrington, Organometallics, 2009, 28, 5661; (e) K. Izod, C. Wills, W. Clegg and R. W. Harrington, J. Organomet. Chem., 2013, 725, 11.

7 K. Izod, C. M. Dixon, E. McMeekin, L. Rodgers, R. W. Harrington and U. Baisch, Organometallics, 2014, 33, 378.

8 E. O. Fischer and H. Grubert, Z. Naturforsch., B: J. Chem. Sci., 1956, 11, 423.

9 (a) B. E. Eichler, A. D. Phillips and P. P. Power, Organometallics, 2003, 22, 5423; (b) C. J. Cardin, D. J. Cardin, S. P. Constantine, S. J. Teat and S. Coles, Organometallics, 1998, 17, 2144; (c) C. Drost, M. Hildebrand and P. Lönnecke, Main Group Met. Chem., 2002, 25, 93.

10 N. N. Greenwood and A. Earnshaw, Chemistry of the Elements, Butterworth-Heinemann, Oxford, UK, 2nd edn, 1997. 